\title{
A METHODOLOGY FOR IMPROVING NEET YOUTH EMPLOYMENT IN THE ICT LABOUR MARKET
}

\author{
Luciana Oliveira, Anabela Mesquita and Adriana José de Oliveira \\ CEOS.PP ISCAP Polytechnic of Porto \\ Rua Jaime Lopes Amorim, s/n 4465-004 S. Mamede de Infesta, Matosinhos, Portugal
}

\begin{abstract}
A global youth employment crisis and the transformation of the ICT labour market has been raising severe concerns and worldwide recommendations for the coordination of cross-field and cross-level agents, as well as the need for coherent strategies based on research and dialogue between workers, employers, organizations and youth groups to decrease the number of NEET. In this context, the Direction Employment project sets as a main objective to promote the integration of underprivileged minorities into the labour market, namely the NEET youth. To address the identified difficulties, an experimental educational and social intervention model was developed and will be implemented in different EU regional contexts, combining innovative pedagogical methodologies with social support structures for young people. This paper presents a methodology for the convergence of the main axis concerning NEET youth unemployment in the ICT labour market, namely educators and trainers, ICT employers and professionals, psychologists and young people, as well as the expected outcomes and key indicators for the assessment of the desired social/professional impact.
\end{abstract}

\section{KEYWORDS}

NEET Youth, Unemployment, ICT Labour Market, Methodology

\section{INTRODUCTION}

Despite the modest recent economic recovery, unemployment remains a major global concern. According to the International Labour Organization (ILO, 2017), unemployment affects especially young people who are entering the job market in record numbers and who are three times as much likely as adults to remain unemployed. A particularly concerning group are the young people who are not in employment, education or training (NEET) and, above all, young women. The youth employment crisis and reducing youth NEET rates is one of the primary targets of the 2030 United Nations Agenda for Sustainable Development Goals (UN, 2015).

The technological unemployment, which regained increased visibility in society and research, as a result of the $4^{\text {th }}$ Industrial Revolution (Avis, 2018), has been causing high social and organizational distress, as it remains uncertain if there will be enough decent employment opportunities for the 25.6 million young persons entering the labour market between 2017 and 2030 (WEF, 2018). In the current combination of industrial revolution and gold rush, countless businesses have been jumping to trends by developing digital applications and platforms designed to monetise the new areas of potential that arise every day. Platformization is indeed one of the 4.0 Industry mega-trends (Baums, 2015), together with big data, and artificial intelligence. This represents both tremendous opportunities for business and organizations and challenges for the constant need to re-skill or up-skill the labour force with hard skills and soft skills, with special impact over the ICT market professionals. It also requires profound social changes to cope with the digitalization of personal and professional life (Gray and Rumpe, 2015, Rintala and Suolanen, 2005).

In the world of labour, however, it would be inappropriate to expect that it is a question simply of 'training' for the 'new digital economy' or of investment in skills and qualifications (Degryse, 2016, EC, 2015). In fact, and concerning youth employment, coordination and coherent strategies are needed based on research and dialogue with workers' and employers' organizations and youth groups (ILO). 
In this paper, we introduce the Direction Employment (DE) project and the corresponding methodology proposal for addressing the youth unemployment crisis in the ICT labour market. The main expected outcomes and key indicators for professional and social impact are also presented and discussed in a call for participation among the researchers, social actors and companies.

\section{THE DIRECTION EMPLOYMENT PROJET}

The DE project sets as a main objective to craft and apply in different EU regional contexts, and within of timeline of 3 years, an experimental educational and social-professional intervention model, which prepares disadvantaged NEET young people for the structural labor market changes and digital transition. The consortium of the project is made up of partners from different sectors - NGOs, higher education, companies - from Bulgaria, Lithuania, Slovenia, Portugal, Ireland and Italy, who have a proven track-record of working for the social and labour market inclusion of young people from marginalized minorities.

The model and methodology are fully oriented towards the ICT labor market and fully aligned with the global tendencies for integral and democratic pedagogy, as well as with the top drivers of the digital transition, e.g. evolving preferences and behaviors of the business sector, globalization and new labor markets opportunities, coping with the increased pressure for learning and relevant knowledge and skills, increased demand for compliance with new and diverse standards and regulations.

The project is targeted to disadvantaged NEET youth aged 20-29 years at the European level, comprising the inclusion of specific groups at the local contexts of the participating countries, such as women, LGBT, immigrants and ROMA. The methodology for addressing the NEET youth unemployment crisis of this specific target is presented in the following section.

\subsection{The 4.0 DE Methodology}

The project's methodology is organized into seven main iterative stages, which combine research, intervention, evaluation and informing/reporting/refinement, as illustrated in Figure 1.

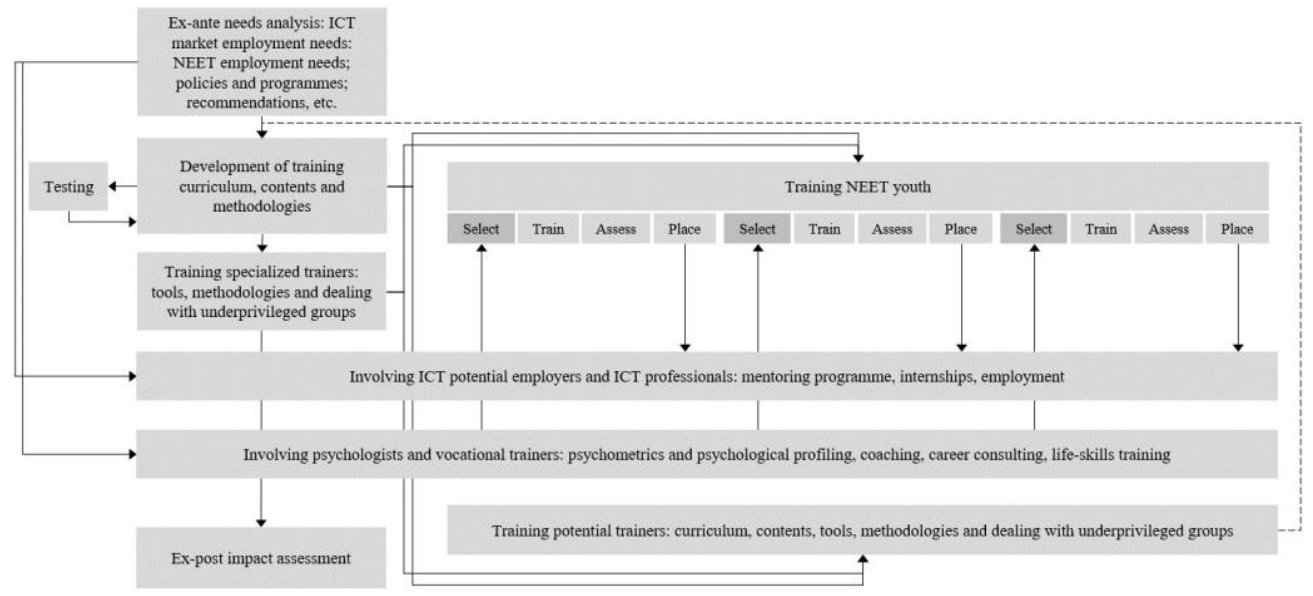

Figure 1. Overview of the 4.0 DE Methodology

The design stages are implemented at the national level, among the project's partners, and the informing/reporting among stages is also conducted transnationally, to benefit continuous improvement based on multicultural settings.

\subsubsection{Ex-ante Needs Analysis}

The first stage of the methodology consists of an ex-ante analysis of the ICT market and NEET youth employment needs, together with existing governmental and non-governmental employment and training policies and programs. This analysis is conducted not only on current needs, but also on future expectations 
and predictions for the ICT labour market and youth training. At this stage, desk research, questionnaires and interviews are conducted to gather quantitative and qualitative data and information that is used to provide recommendations as input for the development of a training curricula, contents and methodologies.

\subsubsection{Development and Testing of Training Curriculum and Contents}

An initial desk research on predictions and future trends for the ICT labour market is conducted during the methodology design, to establish provisional a set of domain areas, at the European level, to be included in the training curriculum. These areas include computer literacy, mathematics and logic, programming and web development. After that, the curriculum is tested with a group of 15 NEET young students and trainers using the short test-class sessions approach. Feedback and follow-ups are collected and reflected in the curriculum, which is, therefore, redesigned and adapted to local contexts. As the final step of the preparation of training, the consortium ensures the certification of the training by appropriate EU or international recognized standards (i.e. ECVET, certificate for vocational training (CP or FP) etc.).

\subsubsection{Implementation of Training and Socio-Professional Support Structures for NETT Youth}

Based on the ex-ante needs analysis and on the developed curriculum and contents, three series of seven months long training of up to thirty participants each are implemented in Europe. Each series is arranged in four main stages, as illustrated in Figure 1: one month for profiling and selection of participants, five months for core training and one final month for examination of competences and placement in the labour market. Psychologists and vocational trainers are involved in the selection phase to conduct psychometrics and psychological profiling, and also during the core training, to provide coaching, career consulting and life-skills training. The involvement of potential employers and professionals begins together with the core training in order to provide mentoring and internships to trainees, though their role is more prominent as labour market entry facilitators.

All through each of the three series of selection, training and placement the NEET youth will be accompanied by psychologists, vocational trainers, potential employers and ICT professionals. This is aimed at nurturing both personal and professional development of NEET youth, as well as building the necessary social settings for their market entry. Together with the vocational training and mentoring, in-family work with parents and siblings, personal development support, training visits, cultural development and meetings with ICT industries are included as continuous support initiatives.

In parallel, analysis of the group and individual experiences will be conducted, and feedback to the education methodologies and trainers will be provided on monthly basis. Reports of learning metrics, such as activity, learning flow, laziness etc., will be provided, and indexes for personal development will be introduced. The initial estimation of the trained NEET young students is 420 , with at least $70 \%$ of the in-class training attended, and at least $90 \%$ of the course hours taken. The foreseen success rate of the trainees is $65 \%$.

\subsubsection{Development and Implementation of Training for Trainers (ToT)}

Together with the development and implementation of training for NETT youth, a mobile smart classroom toolkit for training of potential trainers will also be prepared. The toolkit purpose is to train new trainers, and to transfer the 4.0 DE methodology into new regions of the participating countries. At least 2 new regions per country will be approached, and short-term trainings will be organized in parallel with the NEET youth main training. At least one train of new trainers per take-in (three overall) will be organized using the following structure: 3 months of MOOC combined with 3 days on-site training in preselected regions. The main criteria for selection of a new region will be to have at least 20 trainees enrolled in the course. The course content will be based on the following ToT curriculum modules: (a) how to use the curriculum; (b) how to prepare digital contents; (c) mobile smart classroom toolkit utilization; and (g) working with socially vulnerable groups. The ToT also envisions the creation of synergies among trainers to improve the curriculum, contents and pedagogical strategies for NEET youth training. 


\subsubsection{Ex-post and Impact Analysis}

An ex-post and impact analysis and assessment will be conducted at the end of each of the training cycles, and six months after the NEET youth placement in the labour market. This is to ensure proper analysis and improvement of the methodology, the convenient personal and professional follow-up of trainees in the labour market and the measurement of employment rates and social impact. To do so, the World Bank Social Safeguards methodology and the Aspen Institute Social Impact methodology will be used together with other in-house developed social impact and assessment tools, which will be informed, among others, by peer reviews and empathic deep interviews with NEET trainees, trainers, employers and other stakeholders.

The WBS Safeguards propose, among others, guidelines for the Assessment and Management of Environmental and Social Risks and Impacts which set out responsibilities for assessing, managing and monitoring environmental and social risks and impacts associated with each stage of a project supported by the Bank, in order to achieve environmental and social outcomes consistent with the Environmental and Social Standards (ESSs).

\subsection{Expected Outcomes}

The methodology of the project envisions three main domains of expected outcomes: tangible outputs, research outputs and social impact. The tangible outputs include the development and provision of an education/training model, a curriculum and contexts for the upskilling/reskilling of NEET youth in the ICT labour market and a toolkit/course for training trainers. The research outputs are expected to emerge from the project's methodology, from the synergies established with trainers, stakeholders and researchers as well as from the project's annual international conferences. These consist of methodologies, current state analysis, models, forecasts, revisions, recommendations, assessments and results expressed in tools, reports and scientific publications.

The most relevant expected outcome resides on the potential of the social impact achieved with the methodology of the project, this is why the methodology is key and subject of revision. The evaluation of the social impact will be based on the following key indicators: (1) $52 \%$ of the trainees have received placements; (b) $75 \%$ of the trainees have reported changes in behaviour/self-assessment; and (c) $* 55 \%$ of the employers have reported changes in their perception of the employability of disadvantaged NEET youth, which leads to increased sustainability.

\section{CONCLUSION}

This paper presents a methodology for the convergence of the main axis concerning NEET youth unemployment in the ICT labour market, namely educators and trainers, ICT employers and professionals, psychologists and young people. At his stage, the main contribution relies on the conceptual and practical potential of the methodology to address the needs of the multiple key-players in the integration of NEET youth in the ICT labour market, providing guidelines and procedures for the convergence of synergies that are in line with core European and global recommendations.

Since the methodology design and procedures reunite cross-field and cross-level of domains of expertise, it can be applied to other specific targets for researchers and practitioners aiming at addressing local and global employability issues.

The main limitations of this work, at the stage, reside essentially on the absence of a detailed ex-ante needs assessment as an entry point, which is not yet fully conducted, but which will be presented to the scientific and social community in future research.

\section{ACKNOWLEDGEMENT}

This work is supported by the EEA and Norway Grants for Youth Employment within the project Direction Employment, project index no. 2017-1-294. 


\section{REFERENCES}

Avis, J. 2018. Socio-technical imaginary of the fourth industrial revolution and its implications for vocational education and training: a literature review. Journal of Vocational Education \& Training, 70, 337-363.

Baums, A. 2015. Industry 4.0: we don't need a new industrial policy but a better regulatory framework. Social Europe, 21.

Degryse, C. 2016. Digitalisation of the economy and its impact on labour markets. ETUI Research Paper-Working Paper.

EC 2015. A Digital Single Market Strategy for Europe. European Commission.

Gray, J. \& RUMPE, B. 2015. Models for digitalization. Software \& Systems Modeling, 14, 1319-1320.

Ilo 2017. Global Employment Trends for Youth 2017: Paths to a better working future. Geneva: International Labour Organization.

Rintala, N. \& Suolanen, S. 2005. The implications of digitalization for job descriptions, competencies and the quality of working life. Nordicom Review, 26, 53-67.

UN 2015. Transforming our world: the 2030 Agenda for Sustainable Development. United Nations.

WEF 2018. The Future of Jobs Report 2018. Geneva: The World Economic Forum. 